In: Naamkunde 20 (1988), afl. 1-4, p. 174 - 177.

\title{
Het legaat van J. Van Overstraeten
}

Op 5 oktober 1986 rouwde Vlaanderen om het heengaan op 90-jarige leeftijd van Jozef VAN OVERSTRAETEN, de erevoorzitter van VTB-VAB. De rol die deze grote bezieler van de Vlaamse Toeristenbond - Vlaamse Automobilistenbond gespeeld heeft in de sociaal-culturele ontvoogding van het Vlaamse volk, is genoegzaam bekend $\left(^{1}\right)$.

J. VAN Overstraeten was een veelzijdig man. De neerslag van zijn brede interesse vindt men in allerhande publikaties, steeds de vrucht van intense studie $\left({ }^{2}\right)$. Als stichter-hoofdredacteur van het bondsblad De Toerist (1926) en sinds 1948 ook De Autotoerist, verzorgde hij decennialang rubrieken als „Ons Toeristisch Patrimonium” (belangrijk voor heemkundigen!) en „Zon en schaduw over Vlaanderen”. De succesrijkste rubriek echter, bekend bij het grote publiek, was „Wat betekent mijn familienaam?". Het betreft hier telkens een alfabetische lijst van familienamen uit België, met lokalisering en verklaring. Per aflevering van één bladzijde (twee kolommen), worden een vijftigtal namen verklaard $\left({ }^{3}\right)$. De eerste aflevering leidde VAN OvERSTRAETEN in

( $\left.{ }^{1}\right)$ Naar aanleiding van zijn overlijden verschenen her en der artikels waarin zijn leven en werk belicht worden:

G. Mertens, Zaaien is belangrijker dan oogsten. Bij de dood van Jozef Van Overstraeten. Dialoog 39 (1986), nr. 18, 3-15.

M. VAN LIEDEKERKE -- R. VeRLINDE, Jozef Van Overstraeten, trouw, kordaat, hoffelijk. Wij nr. 41 (1986), 9.

J. GeriTs, Jozef Van Overstraeten (1896-1986), stichter van het Verbond voor Heemkunde. Ons Heem 41 (1987), nr. 1, 37-40.

L. VERBEKE, In memoriam J.V.O. (St.-Truiden 2-5-1896/Leuven 5-10-1986). KVFMededelingen 14 (1986), nr. 3, 18.

Vroeger reeds, bij diens tachtigste verjaardag, tekende Toon Van Overstraeten een portret van zijn beroemde vader in het weekblad De Post:

T. Van Overstraeten, „Die vader van me”. De Post nr. 1418 (9-5-1976), 5-7; 58.

Zijn dood ging ook in de Vlaamse dagbladpers niet onopgemerkt voorbij: hiervan getuigen talrijke artikels o.a. in De Standaard, Gazet van Antwerpen, De Gentenaar...

$\left.{ }^{2}\right)$ J. VAN OVERSTRAETEN publiceerde o.m. tal van toeristische naslagwerken: zijn driedelige Gids voor Benelux, met Gids voor Vlaanderen (1957, 1963 en 1967), De Gids voor Wallonië en het Groothertogdom (1958), De Gids voor Nederland (1959) en De Nederlanden in Frankrijk (1969) verdienen een speciale vermelding.

Zijn interesse voor de lokale geschiedenis uitte zich in de stichting van het heemkundig tijdschrift Het Land van Aalst (1952), waarvan hij tevens het hoofdredacteurschap waarnam.

( $\left.{ }^{3}\right)$ Naarmate VAN OvERSTRAETEN in de loop der jaren de namen uitgebreider toelicht, bevat iedere bladzijde nog een twintigtal lemmata. 
als volgt: „Wetend dat we belang stellen in naamkunde (plaats- en persoonsnamen), hebben lezers ons in de loop der jaren vaak gevraagd om inlichtingen, die we steeds naar best vermogen hebben verschaft. Dit heeft ons sedert lang op het idee gebracht de familienamen onzer leden te verzamelen en - gewaagde onderneming! - te verklaren (in een soort woordenboek, dat ver klaar is)" $\left.{ }^{4}\right)$. Al dadelijk echter bleek de belangstelling voor de nieuwe rubriek en o.m. voor de vele namen die ontbraken zo groot, dat VAN OVERSTRAETEN ertoe overging álle familienamen die voorkomen binnen de Belgische grenzen te behandelen $\left({ }^{5}\right)$.

Allicht onderschatte VAN OVERSTRAETEN destijds in zijn geestdrift de grootse opzet van het uitgeven van een woordenboek van de Belgische familienamen. Waar hij aanvankelijk gehoopt had het woordenboek d.m.v. deze tweewekelijkse bijdragen in twaalf tot vijftien jaar tijd te kunnen publiceren, was hij bij zijn dood slechts gevorderd tot de familienamen beginnend met de letter F-( $\left.{ }^{6}\right)$. Een dertigtal jaar en ca. 700 afleveringen na het verschijnen van de eerste bijdrage, had hij voor zichzelf uitgemaakt dat hij minstens 105 moest worden om het woordenboek met de ,Z" van Zysman te kunnen afsluiten $\left({ }^{7}\right)$.

De omvangrijke materiaalverzameling van Jozef VAN OVERSTRAETEN kwam terecht op het Leuvense Instituut voor Naamkunde. De vele duizenden steekkaarten met naamkundige notities berusten momenteel in het Archief van het Instituut, waar zij kunnen worden geraadpleegd door belangstellenden. Zijn nalatenschap bevat tevens honderden boeken: naast de naamkundige bibliotheek die hij in de loop der jaren opgebouwd heeft, treffen we ook romanliteratuur aan in diverse moderne talen. Deze werken werden voor een gedeelte ondergebracht in de Centrale Bibliotheek van de universiteit; de overige boeken vonden een

$\left({ }^{4}\right)$ J. Van Overstraeten, Wat betekent mijn familienaam? (I) De Toerist/Autotoerist 32 (1953), 16.

( 5 ) J. VAN Overstraeten, Een woordenboek der Belgische familienamen. Limburg 33 (1954), 148-156; 179-189: Dit artikel is de tekst van een lezing die hij hield op het 35ste Congres van het Verbond der geschiedkundige en oudheidkundige kringen van België (Kortrijk 26-30 juli 1953). Deze tekst verscheen eveneens in de Handelingen van het congres (Kortrijk, 1955, blz. 739-754).

$\left.{ }^{6}{ }^{6}\right)$ De laatste aflevering van Wat betekent mijn familienaam? (nr. DCXCIV) in De Autotoerist verscheen in jaargang 34 (1981), nr. 26, blz. 15. De rubriek vond nadien onderdak in het tijdschrift Vlaamse Stam, waar nr. DCXCV verscheen in nr. 6 van jaargang 28 (1982). De rij wordt gesloten met nr. DCCXXXIII (postuum gepubliceerd) in Vlaamse Stam 23 (1987), nr. 6, 328-331, eindigend met de naam Falat.

(7) G. Mertens, Zaaien is ... (zie voetnoot 1), blz. 10. 
plaats in de bibliotheek van het departement Linguïstiek van de Faculteit Letteren en Wijsbegeerte.

Hieronder geven wij een overzicht van de inhoud van VAN OverSTRAETENS antroponymische documentatie. Die toont duidelijk aan hoeveel gegevens deze enthousiaste werker nog in voorraad had voor verdere studie en publikatie. Tevens trachten wij uit het materiaal, in de vorm waarin het tot ons gekomen is, de door VAN OvERSTRAETEN gevolgde werkwijze te reconstrueren.

Verreweg het grootste deel van de nalatenschap bestaat uit een alfabetisch geklasseerde verzameling steekkaarten waarop familienamen opgetekend zijn, zowat 25000 in aantal (vanaf de letter F). Het is moeilijk precies te achterhalen uit welke bronnen VAN OVERSTRAETEN deze namenvoorraad geput heeft. Blijkbaar noteerde hij voortdurend de namen die hij her en der ontmoette, vulde ze aan met varianten, en schreef er reeds een eerste (soms intuïtieve) proeve van verklaring bij. Wanneer hij een gedeelte klaarmaakte voor publikatie, vervolledigde hij het geheel met de namen uit de lijsten van de postrekeningen en de telefoonboeken. Laatstgenoemde bronnen benutte hij tevens voor de gegevens m.b.t. de lokalisering en frequentie van voorkomen van de familienaam: per lemma vermeldt VAN OVERSTRAETEN de gemeenten waarin de naam voorkomt; een systeem van sterretjes duidt het aantal attestaties in de genoemde gemeente aan. Op deze wijze heeft VAN OVERSTRAETEN een belangrijk gedeelte van de Belgische namenschat toegankelijk gemaakt voor naamgeografische studie; vooral met het oog daarop blijft zijn werk o.i. waardevol $\left({ }^{8}\right)$.

Naargelang de publikatie der lijsten vorderde, worden gaandeweg de verklaringen meer uitgediept: VAN OverSTRAETEN neemt o.a. steeds meer historische attestaties van de persoons- en plaatsnamen op, meestal echter zonder vermelding van bron en/of bibliografie. Intussen kunnen we uit de ca. 1000 nagelaten bibliografische notities opmaken welke werken VAN OVERSTRAETEN raadpleegde om tot een ernstige verklaring te kunnen komen. Het is in het bestek van deze bijdrage niet mogelijk deze bibliografische lijst in extenso te publiceren $\left({ }^{9}\right)$. Wel kan worden

$\left({ }^{8}\right)$ Over het naamkundig œuvre van VAN Overstraeten schreef Prof. Draye reeds een appreciatie bij het verschijnen van de 600 ste aflevering van Wat betekent mijn familienaam? Zie Naamkunde 9 (1977), blz. 269-273.

( ${ }^{9}$ Reeds bij de tekst van de genoemde lezing (zie voetnoot 5) voegde VAN OVERSTRAETEN een bibliografisch overzicht waaruit zijn vertrouwdheid met de toenmalige antroponymische en toponymische literatuur blijkt. 
vermeld dat VAN OVERSTRAETEN niet alleen beschikte over een groot aantal standaardwerken en historische en etymologische woordenboeken in diverse talen (o.a. Spaans, Portugees, Deens ...), maar ook een aanzienlijk aantal naamkundige artikels uit gespecialiseerde tijdschriften doorgenomen had.

Tenslotte bevat VAN OverstraETENS legaat een duizendtal steekkaarten met historische inlichtingen over heiligen, martelaren, kerkelijke hoogwaardigheidsbekleders: meestal betreft het een beknopte levensbeschrijving, hun betekenis in de volksdevotie, liturgische feestdag... Ten behoeve van de geïnteresseerden voegde hij bij de talrijke familienamen die teruggaan op heiligennamen dergelijke wetenswaardigheden toe.

Voor Jozef Van Overstraetens levenswerk, het resultaat van talloze uren zelfstudie en ingespannen arbeid, hebben we niets dan waardering en lof. Hij heeft hiermee een leemte in de Belgische antroponymie pogen op te vullen. Moge zijn onvoltooide werk voor andere vorsers een aansporing en een aanzet zijn tot verder onderzoek op het gebied van de persoonsnaamkunde in België.

Leuven.

Ann Marynissen 